\title{
Erratum to: On Hölder continuity of solution maps of parametric primal and dual Ky Fan inequalities
}

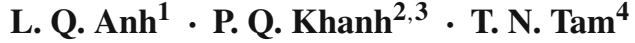

Published online: 20 March 2015

(C) Sociedad de Estadística e Investigación Operativa 2015

\section{Erratum to: TOP DOI 10.1007/s11750-014-0332-1}

A mistake has slipped in the Acknowledgments. The correct version is given below.

Acknowledgments The paper was supported by the National Foundation for Science and Technology Development (NAFOSTED) under grant number 101.01-2014.62. The authors would like to thank the two anonymous referees for their valuable remarks and suggestions, which helped to improve the paper.

The online version of the original article can be found under doi:10.1007/s11750-014-0332-1.

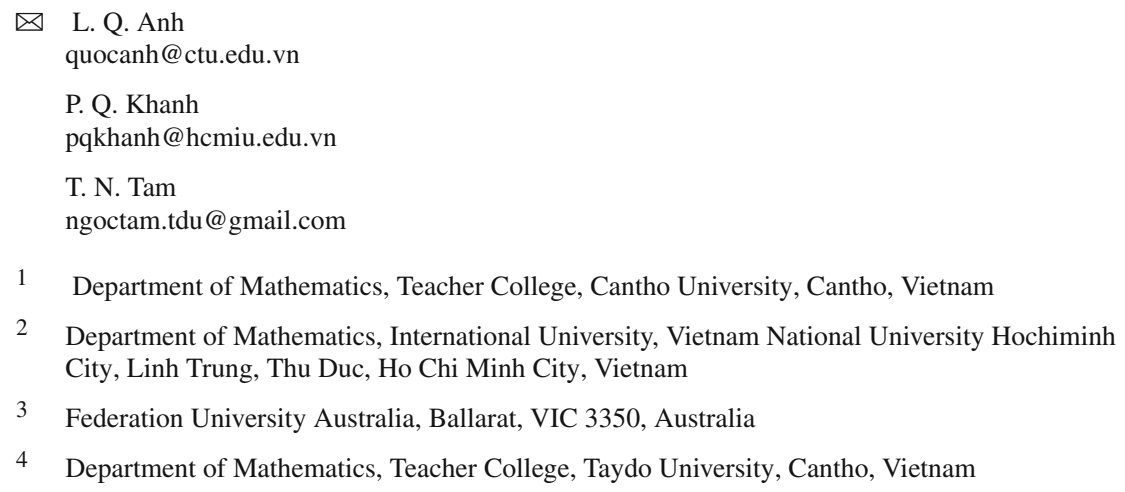

